\title{
ENTERPRISE TECHNOLOGY IN SUPPORT FOR ACCOUNTING INFORMATION SYSTEMS. AN INNOVATION AND PRODUCTIVITY APPROACH
}

\author{
Jose Melchor Medina-Quintero \\ Alberto Mora \\ Demian Abrego \\ Universidad Autonoma de Tamaulipas, Tamaulipas, México
}

\begin{abstract}
Technology and the accounting information systems are implemented in an organization with the aim of improving their efficiency. Companies spend large amounts of money on these tools every year in order to improve their organizational performance. The aim of this research is to determine the influence of SMEs' technological alignment, information management and technological infrastructure on the performance of an institution (innovation and productivity) in which accounting information systems are used. An empirical study is conducted in enterprises belonging to the service, commercial and industrial sectors in Ciudad Victoria, México, with the help of the SmartPLS statistical tool. The results mainly show that technology has helped raise productivity (improvement in administrative activities, in decision-making and in the use of generated information).
\end{abstract}

Keywords: technological alignment, information management, innovation, AIS, productivity

\section{INTRODUCTION}

Accounting is the engine that moves an enterprise forward, and helps it face its competitors' efforts, trade agreements, fiscal issues, etc. The accounting's aim is to mirror an enterprise's state, financial statements, and outcomes. Decision makers in a company benefit from this information when they receive it. For example, they can decide what direction they can give to the company or what policies they can develop. Similarly, information related to accounting is also beneficial for enterprise's partners as a good performance of the company can determine the benefits they will obtain from it. The American Institute of Certified Public Accountants in the United States of America has made a call for the need to incorporate the concepts of information technology (IT) into the accounting professionals' knowledge, skills, and abilities (Dillon and Kruck, 2004). They claim that such competencies should be applied

Manuscript first received/Recebido em: 08/04/2014 Manuscript accepted/Aprovado em: 14/12/2014

Address for correspondence / Endereço para correspondência

Dr. José-Melchor Medina, Universidad Autónoma de Tamaulipas. Centro Médico y Educativo “Adolfo López Mateos” Cd. Victoria, Tamaulipas. México. Phone: (+52) 8343181756 ext. 139. E-mail jmedinaq@uat.edu.mx

Dr. Alberto Mora, Universidad Autónoma de Tamaulipas, Tamaulipas. México. E-mail amora@uat.edu.mx

Dr. Demian Abrego, Universidad Autónoma de Tamaulipas, Tamaulipas. México. E-mail dabrego@uat.edu.mx 
to the organizational performance improvement efforts. To do so, it is fundamental for organizations to be aware of the importance of the accounting function, otherwise, all the financial information may become an underused resource. However, entrepreneurs often raise questions regarding the IT return on investment, specifically, in Accounting Information Systems (AIS), even though there is evidence of their positive impact on various aspects such as productivity and organizational performance, as they help increase sales levels and have access to more customers and improve the relationship with them, raise efficiency levels in the business processes, and decrease cost, among others.

Scholars have been trying to explain the strategic value of IT capabilities for a long time (Fink, 2011). There is ample evidence of the ways in which IT has been applied in the achievement of enterprises' productivity and in helping them become more competitive globally. This enables them to put their human and economic efforts into the development of new products.

The spread of technology is central to an organization's development and change. According to Gordon and Tarafdar (2007), IT entails information, project management, collaboration, communication, and their involvement helps enterprises improve their ability to innovate, as the technological developments are the result of innovative processes. However, Hevner et al. (2004) sustain that there are insufficient constructs, models, methods and tools to represent accurately the link between business and technology. In this context, many small and medium sized enterprises (SMEs) have aligned technological applications with their business operations, but few have been able to successfully integrate IT into their business units (Chen and $\mathrm{Wu}, 2011$ ). A concrete example of this is the case of AIS, which has not been exploited for the benefit of an organization's harmonious development.

SMEs play an important role in most countries' economies. However, when compared to large enterprises, SMEs have a more simple structure, fewer specialized tasks, and fewer resources than those of human, financial and material (Feller et al., 2011). Regarding IT, they do not normally have an IT department; they lack project leaders; and formal IT staff training programs do not exist. In other words, they have scarce resources, and according to the resources and capabilities theory, they need different competencies to be able to face the challenges that the scarcity of resources represents.

In addition to the aforementioned, the knowledge age has had an effect on SMEs. For example, IT has an impact on the accounting based performance, which is determined mainly by their knowledge management capacity (Tanriverdi, 2005), as knowledge is considered a strategic resource within the resource based theory. In other words, SMEs should try to make the most of technology which has become more and more accessible thanks to the constant reduction in costs, which in turn facilitates the justification of the acquisition of IT and AIS.

Nevertheless, it is important to mention that most studies that address this topic have been focused on the context of developed countries (Sabherwal et al., 2006; Petter et al., 2008; Ferreira and Cherobim, 2012). Therefore, there is an urgent need to undertake research that is not only limited to those countries. Scholars such as Mahmood and Mannm (2000) have also suggested the need for other scholars to include the experience of other countries as well.

IT and AIS are undoubtedly of paramount importance nowadays. In the Mexican context, little research into the impact of information systems (IS) and their benefits at the organizational level has been conducted; and this study is an attempt to fill that gap in the literature. Therefore, the aim of this paper is to determine the impact of technological alignment, information management and technological infrastructure on the performance of an institution in terms of innovation and productivity with the daily use of an AIS in the 

approach

SMEs. To achieve this aim, a research model is tested and examined in SMEs belonging to the service, commercial and manufacturing sectors in Ciudad Victoria, Mexico. Data is collected directly from the participating economic units. Such data is in turn analyzed statistically through the use of SmartPLS, developed by Ringle et al. (2005). The research is based on the review of the literature related to the dependent and independent variables studied. After that, the empirical part of the research is carried out (administration of the questionnaire, its analysis and discussion of the main findings). The conclusions are then drawn and the main contributions to knowledge are outlined.

\section{REVIEW OF LITERATURE}

\subsection{INNOVATION}

Innovation affects firms' ability to compete successfully in an increasingly global market (Madrid-Guijarro et al., 2009), as innovation is central to organizations' modernization and transformation (Feller et al., 2011). In this sense, organizations not only need to pay attention to efficiency and productivity, but also they need to promote innovation and their mechanisms to develop it which support knowledge generation, sharing and integration (Albers and Brewer, 2003). These two researchers define innovation as the use of knowledge that offers a new product or service needed by customers. However, the concept of innovation is complex; and from the technological and administrative point of view, it requires time, devotion and investment (Toledo and Zilber, 2012). For Sala-I-Martin et al. (2013), innovation can come through the technological aspect or non-technological knowledge. Basically, the innovation process is connected with the search, experimentation, development and implementation of new products, services, processes, ideas and new organizational approaches. Hsu (2010) summarizes innovation as one new technology idea, application of the existing technology for a new invent and improvement of the existing technology or products. For this paper, innovation occurs when an idea, process, service or product is established in the firm, and it faces competition efficiently.

The impact of innovation on performance (both profitability and growth) is primarily indirect and is instead fueled by IT (Dibrell et al., 2008). During the decade of the 1990's, IT proved to be a particularly powerful innovation tool as it enabled the development of new products and helped improve business processes; but the learning of new creative techniques is an ongoing process within an organization and will result in an improvement of processes, products and methods. This raises the following questions: How to innovate with information technology and AIS in an enterprise? How to gain competitive advantages through AIS? Therefore, those organizations wishing to innovate should cultivate the identification of IT competences (Gordon and Tarafdar, 2007). These same scholars warn that IT and the IS could suffocate creativity and innovation by standardizing, automating and institutionalizing the existing processes and work flows. In the same vein, according to Fink (2011), in order for an enterprise to sustain its competitive advantage, it is essential not to open its resources to imitation or substitution. Similarly, an industry's ability to innovate and gain competitive advantage depends on factors such as R\&D stock, human capital, engagement (of products and people) in international business, and market regulations, among others (Apergis et al., 2008).

Innovation is a variable that needs to be promoted within the institutions, regardless of the benefits already gained through such innovation, of the construction of infrastructure, of the reduction of the macroeconomic instability, or of the improvement of the human resources of the population, especially because all these factors seem to run into diminishing returns (Sala-I-Martin et al., 2013). In this context, Mexico is ranked in the $49^{\text {th }}$ position, which has 
started to become difficult to sustain due to the deceleration of many world economies. In addition to that, there is also the lack of knowledge about the creativity potential to increase the organization's innovative capability; therefore, it is imperative for organizations to incorporate into their hierarchical culture the idea that innovation is important for the institution and stakeholders (Toledo and Zilber, 2012).

Undoubtedly, innovation is a factor that any type of enterprise needs to consider if they are to survive in these changing times. The SMEs are not an exception. This is especially true when there are large amounts of information available generated by AIS which have not been used for the common good in the SMEs. In other words, the SMEs are also required to use the data generated within them, not only to compete, but also to survive. The role that IT and AIS play in helping organizations become innovative is not clear. However, because of the importance of innovation, many scholars have analyzed its roots with the hope of determining what an enterprise should do to become more innovative. No doubt more investment in research and development is needed in order to understand and assess new technology and innovation trends. .

\subsection{PRODUCTIVITY}

Sala-I-Martin et al. (2008) stated that enterprises will depend to a great extent on their ability to adapt themselves to the existing technologies in order to increase their productivity. For this research, productivity enables enterprises to develop better decision-making processes, more effective information and technology usage and more efficient ways to align the organizational strategies with IT.

In addition, as IT has become more important for enterprises, their executives demand more accountability, which requires the measurement of their productivity. In this context, the brief history of the IT shows that they joined the organizations precisely because they promised the automation of monotonous processes and a reduction of staff costs. In other words, they promised an increase in productivity. Nowadays, managers call into question the little benefit they obtain from the financial, human, time and effort investments they make, including all their risks involved in this process. Badescu and Garcés-Ayerbe (2009) found that while organizations have experienced improvements in the work productivity in a reasonable time, but such improvements do not result from the investment made in IT; even, Robert M. Solow, the Nobel Prize winner in 1987, mentioned that "we see the computer era everywhere except in the productivity statistics". This is so because according to Mahmood et al. (2000) investments in computers will be profitable only if they entail an increase in productivity. Nonetheless, the emergence of the IT productivity paradox came to exacerbate this situation due to the huge investments made, which most of the time are not reflected in the organizational productivity. This situation leads to the conclusion that despite the investments in IT, it fails mainly because there is a lack of acceptance of it on the part of its users, an absence of a systematic planning as well as a lack of managers' participation in it.

With respect to the impact of investments in IT, at organizational productivity levels, positive and significant relationships have been observed and recognized lately, especially with the IS and AIS in particular. This situation is even present in those organizations which have been successful in adopting IS; they are normally looking for ways of improving their business processes, considering the IS as a means of increasing productivity (Feller et al., 2011). In another study, Farrell (2003) also recognizes this co-relation, but framed and justified in highly competitive environments, and therefore, with a high demand for innovations; in such environments, innovation and technology transfer have been found to be statistically significant for productivity gains (Apergis et al., 2008). 

approach

Some researchers wonder whether it is possible to maximize IT performance if this is not done simultaneously with the restructuring of organizations; what is not debatable is the fact that investments made in IT may facilitate the complimenting innovations in the economy such as the business processes and the work practices, which leads to an increase in productivity through a cost reduction and quality improvement (Han et al., 2011).

As can be seen, the Productivity variable is very important for small and mediumsized enterprises. AIS may be a source of progress and a generator of organizational productivity if used efficiently. This can be achieved by utilizing all data created through its continuous usage.

\subsection{TECHNOLOGICAL ALIGNMENT}

The alignment between businesses and IT has been defined by Venkatranman (1989) as the relationship between strategy and performance at the information technology service level, as well as at the business level. Based on this concept, IT professionals and business leaders are constantly in pursuit of their best administrative practices so as to be able to align their business strategies with those of technology (Hammett, 2008). Similarly, Henderson and Venkatraman (1993) suggest that the alignment between IT human skills and IT infrastructure capacity has a positive strategic effect; that is why technology has an important role to play in the strategic planning process for the achievement of objectives and mission (Lewis III, 2009). For his part, Davenport (2000) argues that a combination of strategy, technology, data (relevant), organization, culture, skills and knowledge helps develop the organization's capabilities for the data analysis process. The benefits can be even greater if the focus is on the data obtained from an AIS, as this can be an important measure for the development of the strategies aimed at such technological alignment.

The sharing of knowledge between managers and IS professionals is an important factor for the achievement of alignment between business objectives and those of IT. This is especially the case when the management of an organization's technology has been assigned to the IT department; therefore, there needs to be a strategic alignment between business strategies, IT strategies, IS infrastructure and organizational infrastructure (Henderson and Venkatraman, 1993). To do so, there are certain aspects that need to be taken into consideration for the alignment of business with IT (Onita and Dhaliwal, 2011): scope, governance, availability of resources, competences and process. With the current tendencies of evaluation and fiscal audits, accounting cannot be left out in this context. Unfortunately, organizations have not been able to succeed in maintaining a harmonious relationship between business and IT (Hammett, 2008).

While there is a general agreement among practitioners that the alignment of IT and the businesses is necessary, the pathway to achieve it is not completely clear. This is because business strategies are firstly defined and then operations and support strategies, including the technologies are aligned with them (Feurer et al., 2000). For example, Dibrell et al. (2008) argue that IT initiatives should be aligned with innovation. That is to say, in order to obtain a real integration between IT and business strategy, it is necessary that the very process of establishing the strategy incorporates ingredients of IT just as it does with other functions (commercial, sales, production, and others), and according to Peak et al. (2005), this alignment involves the good use of the decisions of the IT resources for the achievement of strategic objectives of the businesses (anticipation to the future requirements), tactics (location of resources) and operational (efficiency and effectiveness achievement) of the organization; because any change in the strategy and technology potentially results in a change in the value system, in the culture and in the structure of the organization teams (Feurer et al., 2000). 
In today's business environment, the alignment of IT with business processes, such as the stakeholders' abilities, constant technological changes, new standards, strategies with competitors, among others is more and more difficult. The integration of IT and IS (which includes AIS) with the enterprise's operations has been widely recognized as a requirement for improving various aspects of an organization.

We need to understand that the alignment of the conduct of the strategic business units within the corporation and the alignment of the organization with IT and then with these units have been a top priority for many managers. Therefore, enterprises need to integrate it into their business plans in order to ensure that they are aligned with their strategy (Galleta and Lederer, 1989) also highlight its important role in the support of management decision making processes. They go on to suggest that SMEs should consider how they can apply IT to other strategic initiatives, such as customer responsiveness, in order to enhance the overall effectiveness of the strategy.

Overall, there are different key factors that contribute to the alignment of organizational strategies with technology in an enterprise. These include their leaders' communication, participation and support in IT, the sharing of knowledge, the clear definition of processes, the technological infrastructure and the integral planning.

After having reviewed the literature on technological alignment, we now proceed to present the hypotheses of our work for this construct. A description of their operationalization is provided in the Method section:

$\mathrm{H}_{1}$. The technological alignment generated through the use of AIS is a means to innovate in an SME.

$\mathrm{H}_{2}$. The technological alignment generated through the use of AIS allows SMEs to increase their productivity levels.

\subsection{INFORMATION MANAGEMENT}

The organizational information processing theory is based on the idea that an organizational adjustment is adequate when the business strategies' information processing requirements are in concordance with the organizational structure's information processing capacity (Jarvenpaa and Ives, 1993). Unfortunately, few SMEs have formally designed their information policies and management (Feller et al., 2011) even though globalization requires the performance of structured and unstructured transactions, and the sharing of information beyond their boundaries.

All enterprises depend on information technology for the accurate and timely management of information. However, many enterprises tend to collect large amounts of data from the entire organization. This raises the following question: Now what do we do with them? According to Oppenheim et al. (2004) information may contribute to the organizational effectiveness. They warn that its impact remains hidden until it is removed or lost. In other words, information makes sense only if someone uses it for something.

Davenport and Prusak (1997) have argued that information plays a role in the facilitation of the exchange process with the value chain as part of its business strategy as its users need it to understand the meaning of the data and virtually, all the stakeholders in the enterprise (operators, executives, etc.) use information to produce more information. Moreover, for enterprises, knowledge management is an essential managerial activity for sustaining competitive advantage in today's information economy (Lin et al., 2012). Nevertheless, knowledge, including information, is also an organizational capability which is a source of a sustainable competitive advantage. As Ray et al. (2005) have stated, those 
enterprises with a high level of knowledge and information sharing achieve good results in offering services to their customers. In this respect, Davenport (2000) introduces the data oriented culture and calls for the need for data analysis, data integrity, data synthesis, complete data and prompt extraction of data. For this reason, AIS are a useful tool for the generation of tangible information which can help create competitive advantages and if treated adequately, they can become a knowledge creation source.

Undoubtedly, information is an intrinsic component in almost all the information activities in every organization to the degree of becoming transparent. This is so because it is the means through which people express, represent, communicate and share their knowledge. Marchand et al. (2002) highlight that it is the use of information which has an influence on the creation of business value through four strategic priorities: $i$ ) Minimizing financial, commercial and operational risks, $i$ i) reducing costs of transactions and processes, iii) adding value to customers and markets, and $i v$ ) creating new realities through innovation.

As can be seen, information management is an information technology trend that is having, or will have, a short-term impact on all types of businesses. Therefore, organizations should implement strategies related to information management technologies if they are to increase their effectiveness, competitiveness and their ability to address competition (Lin et al., 2012).

We now proceed to present the hypotheses of our work for this construct. A description of their operationalization is provided in the Method section:

$\mathrm{H}_{3}$. The information management generated through the use of AIS is a means to innovate in an SME.

$\mathrm{H}_{4}$. The information management generated through the use of AIS allows SMEs to increase their productivity levels.

\subsection{TECHNOLOGICAL INFRASTRUCTURE}

Technological infrastructure allows organizations to develop key applications, and to share information related to division and products (Han et al., 2011). It is defined as the group of interrelated capital resources which provide the foundation on which IT applications are built. It is made up of hardware, software and orgware, which support the AIS that record all the commercial activities of an organization. However, standardizing all the IT infrastructure aspects is not recommended since the business units need autonomy to meet their specific technological needs (Tanriverdi, 2005). The sharing of joint objectives, principles, values and language among the talented IT people in the business units is needed.

The majority of the enterprises view the new technologies as instruments to gain certain advantages and many of the times as tools to bring about a change in the business strategies and the institutional corporate processes. In addition, IT infrastructure is positively associated with the duration of the sustainability of the competitive advantage, although it is not eternal. A constant renewal in IT infrastructure is needed as this has become more and more inexpensive and accessible to all organizations.

It has also been noticed that the promises of IT have not been fulfilled, and the socalled productivity paradox has been called into question, especially due to the big investments made by organizations in computers and technology hoping to obtain a substantial profit (Hitt and Brynjolfsson, 1996), to improve performance, best decision making gains competitive advantage and because of the influence it has on the strategy (Davenport, 2000), for the impact it has on the enterprises and for the changes in the businesses' environment. What is surprising about the paradox is that just when the 
technology adds amazing quantities, it has not been able to respond to the fundamental needs of the enterprise. Imposing a uniform IT strategy and infrastructure through all the business units and centralizing the management of the IT resources may be useful for the central objectives; nevertheless, this can also limit the degree of autonomy and performance of the business (Tanriverdi, 2005).

Similarly, Dibrell et al. (2008) contend that an appropriate use of IT infrastructure may impact positively on innovation, productivity and competitiveness. Yet, some organizations have failed in their attempts, and those enterprises with a high degree of success in the adoption and use of IS were constantly searching for new IT techniques and ways to incorporate them into the organization's business processes (Feller et al., 2011). However, some researchers such as Heo and Han (2003) contradict this claim arguing that IT may lead to an increase in costs and affect management. This study intends to contribute to the debate about these issues.

We now proceed to present the hypotheses of our work for this construct. A description of their operationalization is provided in the Method section:

$\mathrm{H}_{5}$. Technological infrastructure in the way of AIS is a means to innovate in an SME.

$\mathrm{H}_{6}$. Technological infrastructure in the way for AIS to allow SMEs to increase their productivity levels.

\section{METHOD}

Information technology plays a central role in the harmonious development of organizations. Nowadays, it is difficult to conceive an institution without the use of any technology as a means to achieve a certain competitive advantage. In this research in particular, technology is of paramount importance as the literature review carried out in the main research centers and universities in Mexico reveals that there is little, if any, research conducted in this discipline.

The process used to achieve the main objective of the literature review started with a review of the state of the art of the independent variables related to the technological alignment, information management and technological infrastructure. This was followed by a review of the state of the art of the dependent variables related to an organization's performance from an innovation and productivity point of view. The constructs of the independent and dependent variables have been operationalized as follows: through it):

Independent variables (with the use of the AIS and the information generated

Technological Alignment (aims and achievement of objectives, perception of improvement in the performance of activities, definition of strategies in cooperation with organizations and IT), Information Management (strategic use of information, participation of key staff members in information management, continuous acknowledgement of information processes) and Technological Infrastructure (efficiency in operations, relating processes and persons, forecasting market trends, defending the market position).

Dependent variables (with the use of AIS and the information generated through it):

Innovation (select the most promising innovations, making the most of the market opportunities, higher level of products and services innovation), and Productivity 

approach

(perception of activity improvement, information for decision-making, the AIS information is considered as an asset to the organization).

After that, a tentative questionnaire was designed and reviewed by professionals in the field. The instrument was validated by academicians and experts; the next step involved the pre-testing of the instrument, which helped in establishing the validity of the items and their contents. In other words, the administration of pre-tests of the instrument served for improvement purposes, as it requested feedback from the 12 participating enterprises. The results of the pilot test allowed the detection of a few items which did not meet the minimum recommended statistical load. The final version of the instrument was made up of 4 items for the technological alignment section, 3 for information management, 5 for technological infrastructure, 4 for innovation, and 3 for the productivity, in addition to the demographic data section. All of them were assessed in a 5 point Likert scale (Totally Disagree ... Totally Agree), which has more than three values for its measurement as a lower or larger scale will not provide the respondents' discriminating power. The 5 point Likert scale was considered an ideal option since the establishment of acceptable levels of the constructs is critical for any research project. The empirical work was carried out in the central region of the Mexican state of Tamaulipas.

The most recent census conducted by the Mexico's National Institute of Statistics and Geography (INEGI, 2011) shows that there are 5782 SMEs in the state of Tamaulipas (in Mexico, small enterprises are those which have between 11 and 50 employees and mediumsized enterprises are those with a range of 51 and 250 employees). The region under study (Ciudad Victoria) has 636 SMEs. The final version of the instrument was applied to 63 enterprises (10\% of the total population). Unfortunately, the participation of entrepreneurs and managers in this kind of studies in this region is still low. Two questionnaires were applied to each of the enterprises, generating 126 completed questionnaires for their analysis. The respondents were those people who make use of AIS such as the finance manager, the top manager, the main accountant, and the accounting staff. All responses would be kept anonymous and confidential. The criterion for the selection of units of analysis was that the organization had a recognized accounting management function through an AIS.

The data analysis was carried out through descriptive and inferential statistics, with the help of the multivariate SmartPLS (it is PLS variation: Partial Least Squares) software package. This along with a re-sampling of 500 sub-samples allowed us to obtain the crossing of variables, correlation matrices, factorial loadings, average variance extracted (AVE), $t$ statistics, explained variance and standardized coefficient paths. This was done with the purpose of obtaining an answer to the proposed hypotheses. Conclusions are then drawn from the analysis conducted as well as their implications for practice and policy making.

The use of PLS has generated interest among information systems researchers due to the possibility that it offers to model latent constructs under abnormal conditions and with small or medium sized samples (Chin et al., 2003). It is used in a wide variety of disciplines, including economics, political sciences, educational psychology, chemistry and marketing (Fornell and Bookstein, 1982). The aim of the PLS modeling is to predict both latent and manifest dependent variables. Such aim is translated into an attempt to maximize the explained variance $\left(\mathrm{R}^{2}\right)$ of the independent variables. This in turn leads to the fact that the estimations of the parameters are based on the capacity to minimize the residual of the endogenous variables (Cepeda and Roldán, 2004).

SmartPLS will serve as a means to validate the model in an integral form. That is to say, the results of this statistical tool will help determine whether the research model has sufficient reliability. Overall, PLS is an adequate means for research in information systems (Roldán 
and Sánchez-Franco, 2012). To do so, the measurement and structural parameters are estimated simultaneously (analyzed and interpreted in two stages): PLS enabled researchers to assess the measurement model (psychometric properties of the scale used to measure a variable), and the estimation of the structural model (the strength and direction of the relationships between variables). In addition to that, PLS has few restrictions regarding measurement scales, sample size and residual distributions. Therefore, it is more appropriate to explain complex causal relationships (Chen and $\mathrm{Wu}, 2011$ ), especially when there is little theoretical information available (Roldán and Sánchez-Franco, 2012).

\section{A. MEASUREMENT MODEL}

- Reliability: For the purposes of this research, it is assessed by examining the loadings $(\lambda)$ or simple correlations. In order for an indicator to be accepted, it needs to possess an equal or greater loading than $0.707\left(\lambda^{2}, 50 \%\right.$ of the explained variance).

- Internal Consistency (Constructs Reliability), it is assessed by a Cronbach's alpha of (0.7). In this case, the statistic proposed by Fornell and Larcker (1981) is used. Based on their research, these authors claim that their 0.707 measure is greater than that of Cronbach's.

- Discriminant Validation: For this assessment, the square root of the AVE is used (Fornell and Larcker, 1981), which should be greater than the shared variance between the construct and the other constructs in the model. The corresponding matrix provides these values.

- Convergent Validity: This assessment was conducted through the AVE; its values should be greater than 0.50 , which implies that more than $50 \%$ of the construct variance is due to its indicators (Fornell and Larcker, 1981). It can only be applied to reflective indicators (Chin, 1998a).

\section{B. STRUCTURAL MODEL}

The structural model assesses the weight and magnitude of the relationships (hypotheses) among the different variables. For this assessment, two basic indexes are used: the explained variance $\left(R^{2}\right)$ and the standardized path coefficients $(\beta) . R^{2}$ indicates the explained variance by the construct within the model; it should be equal or greater than 0.1 , as lower values, even if they are significant, provide little information, and represent the measure of the predictive power (Roldán and Sánchez-Franco, 2012). The $\mathrm{R}^{2}$ provides an indication of the predictive ability of the independent variables, as well as the standardized path. $\beta$ represents the path coefficients, which has been identified in the monogram (SmartPLS figure) with the arrows that link the constructs in the internal model. This coefficient is obtained in the traditional way (as multiple regression). Chin (1998a) suggests that in order for the standardized path coefficients to be considered significant, they should achieve at least a value of 0.2 , and ideally be greater than 0.3 ; in addition to that, Chin (1998b) considers $\mathrm{R}^{2}$ values of $0.67,0.33$, and 0.19 as substantial, moderate, and weak respectively.

\subsection{RESULTS}

From the 126 valid questionnaires, the gender distribution was $78 \%$ woman and $22 \%$ men. The Age rank was classified into four levels: Up to 20 years old (9\%), 21-30 years old (83\%), 31-40 years old (4\%), 41-50 years old (3\%) and 51 or more years old (1\%). Use of the system (weekly), five groups came from the sample: 0-10 hours (22\%), 11-20 hours (31\%), 21-30 hours $(21 \%), 31-40$ hours $(18 \%)$, and 41 or more hours $(8 \%)$. Regarding educational level: high school $(7 \%)$, undergraduate $(83 \%)$, graduate $(10 \%)$. And finally, the sector to 

approach

which the participating enterprises belong: service (85\%), commercial (12\%) and industry $(3 \%)$.

\section{A. MEASUREMENT MODEL}

- Reliability: The indicators present acceptable values, including the 19 reflective indicators (Table 1); the loading factor varies between 0.7079 and 0.9073 , surpassing the minimum requirements of 0.707 .

- Internal Consistency (Constructs Reliability): Table 1 shows that the internal (composite) reliability is given in this research, surpassing the minimum requirements in the Fornell statistical of 0.707 .

- Discriminant Validity: In order to value the discriminant validity (Table 2), the AVE square root was used (the numbers in bold on the diagonal line are the square root of the variance shared between the constructs and their measures). The variables satisfy the necessary condition; thus adequate discriminant validity was achieved.

- Convergent Validity: The convergent validity of the survey measurement was right (Table 1), AVE exceeds in everything the 0.50 (the values are valuating from 0.6071 until 0.8019). Re-sampling was coming out (500) for getting the T-statistic values; the results showed that almost everyone was significant (Table 3).

Table 1. Individual reliability of the reflective indicators' loading and coefficients' convergent validity

\begin{tabular}{|c|c|c|c|c|c|}
\hline Construct & $\begin{array}{c}\text { Item } \\
\text { Loading }\end{array}$ & $\begin{array}{l}\text { Composite } \\
\text { Reliability }\end{array}$ & $\begin{array}{l}\text { Cronbach's } \\
\text { Alpha }\end{array}$ & AVE & $\mathbf{R}^{2}$ \\
\hline \multicolumn{2}{|c|}{ Information Management } & 0.8968 & 0.8276 & 0.744 & NA \\
\hline IM_1 & 0.7962 & & & & \\
\hline IM_2 & 0.8842 & & & & \\
\hline IM_3 & 0.9034 & & & & \\
\hline \multicolumn{2}{|c|}{ Technological Alignment } & 0.8837 & 0.8248 & 0.6553 & NA \\
\hline Alig_1 & 0.7651 & & & & \\
\hline Alig_2 & 0.8130 & & & & \\
\hline Alig_3 & 0.8308 & & & & \\
\hline Alig_4 & 0.8275 & & & & \\
\hline \multicolumn{2}{|c|}{ Technological Infrastructure } & 0.8848 & 0.8392 & 0.6071 & NA \\
\hline TI_1 & 0.7956 & & & & \\
\hline TI_2 & 0.8074 & & & & \\
\hline TI_3 & 0.7077 & & & & \\
\hline TI_4 & 0.8662 & & & & \\
\hline TI_5 & 0.7079 & & & & \\
\hline \multicolumn{2}{|l|}{ Innovation } & 0.9418 & 0.9177 & 0.8019 & 0.345 \\
\hline Inno_1 & 0.8917 & & & & \\
\hline Inno_2 & 0.9073 & & & & \\
\hline Inno_3 & 0.8998 & & & & \\
\hline Inno_4 & 0.8829 & & & & \\
\hline \multicolumn{2}{|l|}{ Productivity } & 0.8831 & 0.8003 & 0.7161 & 0.522 \\
\hline Prod_1 & 0.7895 & & & & \\
\hline Prod_2 & 0.8641 & & & & \\
\hline Prod_3 & 0.8823 & & & & \\
\hline
\end{tabular}


Table 2. Correlation of variables (discriminant validity)

\begin{tabular}{|r|l|l|l|l|l|}
\hline & IM & Alig & TI & Innov & Prod \\
\hline IM & $\mathbf{0 . 8 6 2 6}$ & & & & \\
\hline Alig & 0.6316 & $\mathbf{0 . 8 0 9 5}$ & & & \\
\hline TI & 0.5172 & 0.5700 & $\mathbf{0 . 7 7 9 1}$ & & \\
\hline Innov & 0.5568 & 0.4973 & 0.3380 & $\mathbf{0 . 8 9 5 5}$ & \\
\hline Prod & 0.5940 & 0.6327 & 0.6060 & 0.4941 & $\mathbf{0 . 8 4 6 2}$ \\
\hline
\end{tabular}

Note: elements on the diagonal line are the result of the square root of AVE. For the discriminant validity, these values should exceed the inter-construct correlations. IM (Information Management), Alig (Technological Alignment), TI (technological infrastructure), Innov (Innovation) and Prod (Productivity).

\section{B. STRUCTURAL MODEL}

Table 3 shows every planning hypothesis; in Figure 1, they are detailed in a graphic form, showing the research model evaluated empirically; they also show that the values obtained are within the ranks of the previous parameters.

Table 3. Summary of SmartPLS results

\begin{tabular}{|l|c|l|c|}
\hline \multicolumn{1}{|c|}{ Hypothesis } & $\begin{array}{c}\text { Coefficient } \\
\text { Path }\end{array}$ & T-statistic & Remarks \\
\hline Technological Alignment $\rightarrow$ Innovation & 0.246 & $2.000 *$ & Supported \\
\hline Technological Alignment $\rightarrow$ Productivity & 0.353 & $3.039 * *$ & Supported \\
\hline Information Management $\rightarrow$ Innovation & 0.358 & $2.919 * *$ & Supported \\
\hline Information Management $\rightarrow$ Productivity & 0.250 & $2.176 *$ & Supported \\
\hline Technological Infrastructure $\rightarrow$ Innovation & 0.014 & 0.532 & Not Supported \\
\hline Technological Infrastructure $\rightarrow$ Productivity & 0.365 & $3.343 * * *$ & Supported \\
\hline
\end{tabular}

\section{Figure 1. Research Model}

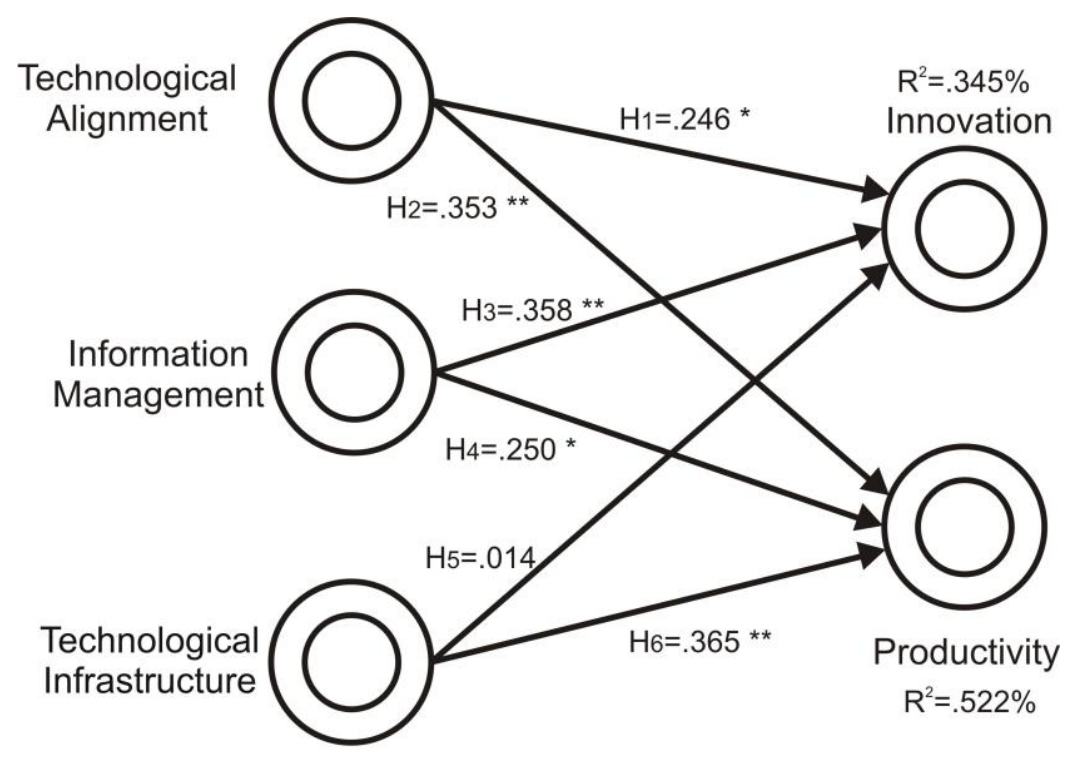

$$
\begin{aligned}
& \text { *** } p<0.001 \\
& t=3.31012457 \\
& \begin{array}{l}
{ }^{* *} p<0.01 \\
t=2.585711627
\end{array} \\
& \text { * } p<0.05 \\
& t=1.964726835
\end{aligned}
$$


The data analysis suggests that all investments in AIS made by the managers has influenced the employees' perception that there has been an increase in productivity. Employees perceive a substantial improvement in the development of activities and processes; this means that the information generated is being used to make more and better decisions. Such information is represented as an additional asset in organizations, which can become a means to information management in the short or medium term. Similarly, it has helped make planning based on organizational needs and IT, in which staff members of both parties participate actively in their best interest and their enterprises'. A close monitoring of market trends is also performed.

With respect to innovation, the results indicate that the SME's attempt to improve their activities and the few innovations (administrative, processes and products/services) they have. However, they make a conservative use of their information. Unfortunately, the technological base in place is not the most adequate or it is not used efficiently for their own benefit.

\section{CONCLUSIONS}

AIS have become an essential tool in today's businesses. Therefore, organizations continue to invest in these technologies as a measure to improve their performance. The aim of this research is to determine the influence that enterprises' technological infrastructure has on their organizational performance from an innovation and productivity point of view through the daily use of an AIS.

Productivity is one of the main demands from the managers; nevertheless, they may be satisfied as such productivity has been achieved through the daily use of AIS, both to be able to provide information requested by government entities and to generate data to be able to face competition. This is especially true when it comes to the employees' perceptions of the improvement in the activities they perform, information to be able to make more and better decisions and, above all, to create the culture of the importance of an appropriate use of information which can lay the foundations for the discussion about knowledge management. For that reason, the investment made in IT is justified, calling into questioning the productivity paradox, at least for these enterprises under study. However, as has been said, IT and productivity are not everlasting; a constant innovation is needed, which involves further investments in hardware, software and, above all, in people.

Similarly, it is important to point out that, just as productivity, there has been a significant progress in innovation. Nevertheless, such innovation is not necessarily technology related; but the SMEs intend to improve their administrative processes through AIS (their generated data), which in turn is reflected mainly on the products quality/services they commercialize or sell.

Finally, the results show that SME's have inadequate technological infrastructure. However, it is important to make clear that no evidence is available from our research that can explain whether such inadequate technological infrastructure has to do with obsolete technology, inappropriate use, lack of it, little training, among other factors that can account for this users' perception. Likewise, overall, technological infrastructure which includes alignment, information management and technological infrastructure itself do not seem to be of any help for enterprises to be able to efficiently face competition. Therefore, this issue requires special attention on the part of the participating enterprises. It can be argued that these enterprises are facing competition through efficiency in administrative processes, quality service and higher levels of productivity; unfortunately, they appear to be merely 
responding to market needs, rather than doing it in a systematic way which may result in greater and better benefits for the organization.

\section{LIMITATIONS AND FURTHER RESEARCH}

This study has some limitations, which must be acknowledged. First, given that research data represents one snapshot in time, the validity of a model can not be established on the basis of a single study. Second, the study was carried out in a specific geographical context of the northeastern region in Mexico, and was focused on one single type of information systems (accounting). Therefore, care needs to be taken when making generalizations of the results. Furthermore, critiques of the cause and effect relationships among the constructs in the model need to be made with caution. For this reason, other researchers should add other IS and IT success factors that can assist in the development of more specific theories in this respect. Such theories might help managers make more informed decisions regarding investment in AIS. This in turn can increase the likeliness of securing a positive impact of investments made in technology.

\section{REFERENCES}

Albers, J.A., and S. Brewer, 2003. Knowledge management and the innovation process: The Eco-Innovation Model. Journal of Knowledge Management Practice, 4, pp. 1-10

Apergis, N., C. Economidou, and I. Filippidis, 2008. Innovation, technology transfer and labor productivity linkages: Evidence from panel of manufacturing industries. Review of World Economics, 144(3), pp. 491-508

Badescu, M., and C. Garcés-Ayerbe, 2009. The impact of information technologies on firm productivity: Empirical evidence from Spain. Technovation, 29(2), pp. 122-129

Cepeda, C. y J.L. Roldán, 2004. Aplicando en la Práctica la Técnica PLS en la Administración de Empresas. Congreso de la ACEDE 2004. Septiembre 19, 20 y 21. Murcia, España

Chen, Y.C., and J.H. Wu, 2011. IT management capability and its impact on the performance of a CIO. Information \& Management, 48, pp. 145-156

Chin, W.W., 1998a. Issues and opinion on Structural Equation Modeling. MIS Quarterly, 22(1), pp. vii-xvi

Chin, W.W, 1998b. The partial least squares approach to structural equation modelling. In: Marcoulides, GA. (Ed.), Modern methods for business research (pp. 295-336). Nahwah, NJ: Lawrence Erlbaum

Chin, W.W., B. Marcolin, and P. Newsted, 2003. A Partial Least Squares latent variable modeling approach for measuring interaction effects: Results from a Monte Carlo simulation study and an electronic-mail emotion/adoption study. Information Systems Research, 14(2), pp. 189-217

Davenport, T. H., 2000. Mission critical: Realizing the promise of enterprise systems. Boston, MA: Harvard Business School Press

Davenport, T.H., and L. Prusak, 1997. Information ecology. Mastering the information and knowledge environment. Oxford University Press, New York, USA

Dibrell, C., P.S. Davis, and J. Creig, 2008. Fueling innovation through information technology in SMEs. Journal of Small Business Management, 46(2), pp. 203-218 

approach

Dillon, T.W., and S.E. Kruck, 2004. The emergence of accounting information systems programs. Management Accounting Quarterly, 5(3), pp. 29-36

Farrell, D., 2003. The real new economy. Harvard Business Review, 81(10), pp. 104-112

Ferreira, R., and A. Cherobim, 2012. Impacts of investments in it on the organizational performance of baking companies of minas gerais state: a multicase study. Revista de Administração e Contabilidade da Unisinos, 9(2), pp. 147-161

Feller, J., P. Finnegan, and O. Nilsson, 2011. Open innovation and public administration: transformational typologies and business model impacts. European Journal of Information Systems, 20, pp. 358-374

Feurer, R., K. Chaharbaghi, M. Weber, and J. Wargin, 2000. Aligning strategies, processes, and IT: A case study. IEEE Engineering Management Review, 17(1), pp. 23-34

Fink, L., 2011. How do IT capabilities create strategic value? Toward greater integration of insights from reductionistic and holistic approaches. European Journal of Information Systems, 20, pp. 16-33

Fornell, C., and D.F. Larcker, 1981. Evaluating Structural Equation Models with unobservable variables and measurement error. Journal of Marketing Research, 18(1), pp. 3950

Fornell, C., and F. Bookstein, F., 1982. Two Structural Equation Models: LISREL and PLS Applied to Consumer Exit-Voice Theory. Journal of Marketing Research, 19(4), pp. 440-445 Galleta, D., and A.L. Lederer, 1989. Some cautions on the measurement of user information satisfaction. Decision Sciences, 20(3), 419-438

Gordon, S.R., and M. Tarafdar, 2007. How do a company's information technology competences influence its ability to innovate? Journal of Enterprise Information Management, 20(3), pp. 271-290

Hammett, B.M., 2008. Corporate startegy and technology alignment factors that contribute to strategy and technology aligment. Doctoral dissertaion. Capella, University

Han, Ch., Ch. Hsieh, F. Lai, and X. Li, 2011. Information technology investment and manufacturing worker productivity. Journal of Computer Information Systems, 52(2), pp. 5160

Henderson, J., and N. Venkatraman, 1993. Strategic alignment: Leveraging information technology for transforming organizations. IBM Systems Journal, 32(1), p. 4-16

Hevner, A.R., S.T. March, and J. Park, 2004. Design science in information systems research. MIS Quarterly, 28(1), pp. 75-104

Heo, J., and I. Han, 2003. Performance measure of Information Systems (IS) in evolving computing environments: An empirical Investigation. Information \& Management, 40(4), pp. 243-256

Hitt, L.M., and E. Brynjolfsson, 1996. Productivity, business profitability, and consumer surplus: Three different measures of information technology value. MIS Quarterly, 20(2), pp. 121-142

Hsu, J., 2010. Effectiveness of technology transfer measures in improving SME productivity: An empirical study of Taiwan. The Journal of American Academy of Business, 15(2), pp. 206211

Inegi, 2011. Directorio Estadístico Nacional de Unidades Económicas (DENUE). http://gaia.inegi.org.mx/denue/viewer.html. Consulted: Nov 3, 2013

Jarvenpaa, S.L., and B. Ives, 1993. Organizing for global competition: The fit of information technology. Decision Science, 24(3), pp. 547-580 
Lewis III, N., 2009. Identifying critical dimensions that shape the business and information technology alignment process: A case study of a university. Doctoral Dissertation, Capella University

Lin, Ch., J. Wu, and D.C. Yen, 2012. Exploring barriers to knowledge flow at different knowledge management maturity stages. Information \& Management, 49, pp. 10-23

Madrid-GUIJARRO, A., D. Garcia, and H. Van Auken, 2009. Barriers to innovation among Spanish manufacturing SMEs. Journal of Small Business Management, 47(4), pp. 665-487

Mahmood, M.A., J.M. Burn, L.A. Gemoets, and C. Jacquez, 2000. Variables Affecting Information Technology End-User Satisfaction: A Meta-analysis of the Empirical Literature. International Journal of Human Computer Studies, 52(4), pp. 751-771

Marchand, D., W. Kettinger, and J. Rollins, 2002. Information Orientation: The best link to business performance. Oxford University Press, USA

Oppenheim, Ch., J. Stenson, and R.M.S. Wilson, 2004. Studies on Information as an Asset III: Views of Information Professionals. Journal of Information Science, 30(2), pp. 181-190

Onita, C., and J. Dhaliwal, 2011. Alignment within the corporate IT unit: An analysis of software testing and development. European Journal of Information Systems, 20, pp.48-68

Peak, D., Guynes, C.S., and Kroon, 2005. Information technology alignment planning - A case study. Information \& Management, 42(3), pp. 619-633

Petter, S., W. DeLone, and E. McLean, 2008. Measuring information systems success: models, dimensions, measures, and interrelationships. European Journal of Information Systems, 17, pp. 236-263.

Ray, G., W.A. Muhanna, and J.B. Barney, 2005. Information technology and the performance of the customer service process: A resource-based analysis. MIS Quarterly, 29(4), pp. 625652

Ringle, Ch.M., S. Wende, and A. Will, 2005. SmartPLS 2.0 (beta). http://www.smartpls.de. Consulted: May 10, 2013

Roldán, J.L., and M.J. Sánchez-Franco, 2012. Variance-based Structural Equation Modeling: Guidelines for using Partial Least Squares in information systems research. In Mora et al. (ed). Research Methodologies Innovations and Philosophies in Software Systems Engineering and Information Systems, pp. 193-221. IGI Global, Hershey: PA

Sala-I-MARTIN, X., J. Blake, M. Drezeniek, T. Geiger, I. Mia, and F. Paua, 2008. The Global Competitiveness Index: Prioritizing the Economic Policy Agenda, In The Global Competitiveness Report 2008-2009. Ed. Porter, M., and L. Schwab. World Economic Forum. Switzerland

Sala-I-MARTIN, X., B. Bilbao-Osorio, J. Blanke, R. Crotti, M. Drezeniek, T. Geiger and C. Ko, 2013. The Global Competitiveness Index 2012-2013: Strengthening Recovery by Raising Productivity. In The Global Competitiveness Report 2012-2013. Ed. K. Schwab. World Economic Forum. Switzerland

Sabherwal, R., A. Jeyaraj, and C. Chowa, 2006. Information system success: Individual and organizational determinants. Management Science, 52(12), pp.1849-1864.

Tanriverdi, H., 2005. Information technology relatedness, knowledge management capability, and performance of multibusiness firms. MIS Quarterly, 29(2), pp. 311-334

Toledo, L.A., and M.A. Zilber, 2012. An analysis of the fallacy of taking apart technology and innovation. Revista de Administração e Inovação, 9(1), pp. 211-230

Venkatranman, N., 1989. The concept of fit in strategy research: Toward verbal and statistical correspondence. Academy of Management Review, 14(2), pp. 423-444 